\title{
Drop-in biofuels from the co-pyrolysis of grape seeds and polystyrene
}

\section{O. Sanahuja-Parejo, A. Veses*, M.V. Navarro, J.M. López, R. Murillo, M.S. Callén, T.}

\section{García}

Instituto de Carboquímica (ICB-CSIC), C/ Miguel Luesma Castán, 50018 Zaragoza, Spain.

*Corresponding author: a.veses@icb.csic.es

Keywords: Co-pyrolysis; Drop-in fuels; Lignocellulosic biomass; Grape seeds; Polystyrene

\begin{abstract}
Co-pyrolysis of grape seeds and polystyrene was conducted in a fixed-bed reactor, followed by an analysis of the organic phase for possible further application as a drop-in fuel. Significant positive synergistic effects were found with the addition of polystyrene $(5-40 \mathrm{wt} \%)$ to the conventional pyrolysis of grape seeds. There was a considerable improvement in the organic phase yield, in particular, reaching values over $80 \mathrm{wt} \%$, markedly higher than those obtained from conventional pyrolysis $(61 \mathrm{wt} \%)$. Fuel properties of the bio-oil were also upgraded, with a decrease in oxygen content and an increase in the heating value. An organic bio-oil fraction with $\mathrm{pH}$ values ranging from 5.4 to 6.2 was obtained, reducing the issues associated with handling bio-oils obtained from common pyrolysis of lignocellulosic biomass, usually ranging between 2 and 3. Finally, an increment in the desired compounds, mainly aromatics, was also attained, while at the same time achieving a low content of undesired compounds, such as phenols. It was demonstrated that polystyrene can act as a $\mathrm{H}_{2}$-donor, favoring oligomerization, cyclation and hydrodeoxygenation reactions into aromatic compounds.
\end{abstract}

\section{Introduction}

Industrial, social and economic development worldwide is demanding greater amounts of energy, thus posing problems for environmental and energy management. The huge demand for energy has been depleting fossil resources, leading to a negative environmental impact. Due to all these problems, more sustainable and environmentally friendly alternatives are being studied 
where lignocellulosic biomass, the world's largest renewable energy source, emerges as a potential candidate to minimize these adverse effects.

Within lignocellulosic biomass, the use of agricultural residues, such as grape seeds (GSs) from the wine industry, may have a positive environmental impact. It has been demonstrated that GSs especially have a high energy content that makes them attractive as a source of renewable energy [1]. Currently, wine production is very high, with some of the leading countries such as France, Italy and Spain generating around 20 million tons of grapes per year [2], approximately $15-25 \%$ of which ends up as waste, such as skins, stems and seeds, and suitable for processing $[3,4]$. Currently, most of GSs are incorporated again into the vineyards to complete the carbon cycle [3]. However, a great proportion of this residue is still disposed in landfills leading to an inefficient alternative in waste management. In addition, the presence of GSs together with the remaining residues from grapes production in landfills results adverse for the environment. This is mainly due to the presence of phenolic compounds decreasing the $\mathrm{pH}$ and increasing resistance to biological degradation [5] as well as due to the leachates of tannins and other compounds entailing soil and ground water pollution [6]. Hence, due to the potential market applications for the production of value-added products, the use of GSs in for the production of value-added products could emerge as a promising opportunity in the post-treatment of GSs.

The conversion of biomass into valuable chemical products and/or fuels can be conducted through biological and thermochemical technologies, with the latter having become more important, since it is faster than the biological processes [7]. Thermochemical technology can be divided into combustion, liquefaction, gasification and pyrolysis; pyrolysis is regarded as the most cost-effective process, since it can generate value-added products and liquid fuels (bio-oil) with high fuel/raw material rates [7] in one simple step. In fact, the application of different mixtures of these bio-oils with commercially available fuels, such as diesel or gasoline, which are commonly referred to as drop-in fuels, emerges as one of the most promising applications in the field in the short-term $[8,9]$. 
Moreover, the technology can be used to obtain a solid fuel (char) and a non-condensable gas fraction (commonly $\mathrm{H}_{2}, \mathrm{CO}, \mathrm{CO}_{2}$ and $\mathrm{CH}_{4}$ ). Both fractions can be used either as a fuel to support the intrinsic process or in other commercial applications [10]. The process is conducted in an inert atmosphere at moderate temperatures $\left(450-600^{\circ} \mathrm{C}\right)$, with up to about $70 \mathrm{wt} \%$ of biooil being produced depending on experimental conditions, structure of the biomass and reactor technology [11]. Although this product can be considered the main and more valuable one, it presents several disadvantages preventing its direct application as a drop-in fuel. Thus, the challenge of any pyrolysis process to produce drop-in fuel lies in improving the quality of the bio-oil, since these are a complex mixture of oxygenated compounds that cause high acidity, instability and poor heating value $[12,13]$.

Different strategies are being studied focusing on this target. Potential solutions can be divided in ex situ and in situ processes with the latter being the more simple, more efficient and lowercost technology for the production of drop-in fuels. One of the most promising approaches centers on incorporating different waste polymers into the process [14], which act as hydrogen donors and hence, enhance the $\mathrm{H}_{2}$-transfer reaction into desired compounds, thus improving the quality and stability of bio-oil.

From the latest investigations carried out in the co-pyrolysis of the biomass with polymers [7, 14], it can be concluded that bio-oils with a lower oxygen content and, consequently, a higher heating value can be obtained in a single step. Moreover, this achieves a significant increase in the aromatic hydrocarbon yield, which has been linked mainly to hydrogen transfer and radical interaction mechanisms. However, although co-pyrolysis of biomass and waste polymers can be thought of as a promising technology for bio-oil upgrading, further studies are needed to produce bio-oils that could be used as drop-in biofuels.

Within the plastic waste management, polystyrene (PS) could be considered a particularly valuable residue, as its relative abundance presence in municipal plastic waste (MPW) [15] could contribute in a great extent on the waste-to-energy conversion. Particularly, food processing and packaging industry is also one of the main sources of production of this plastic 
[16]. At this point, it must be pointed out that several selective MPW separation technologies such as mechanical or wet separation, and optical sorter technologies have been already investigated and positively implemented for an efficient MPW separation [17, 18]. PS is made of styrene monomers with a chemical structure comprising long hydrocarbon chains with phenyl groups $[19,20]$. Interestingly and, as other authors have concluded, the only way the PS waste can be fully utilized is through pyrolysis, so that it can be turned into a more valuable oil product rather than ending up in the landfills permanently [19]. Several researchers have attempted to carry out the co-pyrolysis process of lignocellulosic biomass with polystyrene. Shadangi et al.[21] studied co-pyrolysis of PS wastes with two types of biomass in different proportions using a semi-batch lab-scale. The results confirmed that this process had a positive influence on the yields and quality of the oil, which was especially reflected in improved viscosity and a higher heating value of the upgraded bio-oils. Hassan et al.[22] found that the addition of PS to torrefied wood significantly reduced the yield of oxygenated compounds, while more aromatic hydrocarbons were produced when using a 5200 model micro-reactor pyrolyzer. In another work, Abnisa et al.[23] studied various mixtures of palm shell and PS in an attempt to optimize operational conditions using a lab-scale stainless steel tubular reactor. Again, higher liquid yields and better oil properties, such as lower oxygen content and higher heating value, were obtained. However, there is still a need for a wide range of studies to define the optimal parameters, such as biomass/PS ratio [24]. It was also concluded from the studies that the type of biomass could have a significant influence. Thus, the study of co-pyrolysis with GSs as a lignocellulosic biomass may be an attractive solution. In addition, since co-pyrolysis of GSs and PS has not been studied thoroughly as a potential solution to producing drop-in fuels, an optimization study at lab-scale would provide a starting point and a necessary step toward further studies on a larger scale.

In this study, co-pyrolysis of GSs and PS was carried out in a fixed-bed reactor plant. Different GSs-to-PS ratios (from 5 to $40 \mathrm{wt} \%$ of PS) were tested and the influence of this parameter on 
the quality of the bio-oil obtained was also evaluated, in addition to analyzing the potential synergistic effects produced in yields and liquid properties.

\section{Materials and methods}

\subsection{Biomass, polystyrene}

Grape seeds (Vitis vinifera), obtained in the northeast of Spain, were used as lignocellulosic biomass in this research. The fresh biomass was previously dried following standard methods at $105{ }^{\circ} \mathrm{C}$ [25] to moisture levels below $2 \mathrm{wt} \%$, and then used directly. On the other hand, waste PS was obtained from that destined for food storage, such as expanded polystyrene trays. Prior to the experiments, the PS size was reduced to between 2-4 $\mathrm{mm}$. The main characterization of the raw materials is summarized in Table 1.

The heating value of both materials was measured experimentally with an IKA C-2000 calorimetric bomb using the Spanish (UNE) standard procedure UNE 164001 EX. Proximate analysis of the feedstock was determined according to UNE-EN ISO 18134-3 for moisture, UNE-EN ISO 18122 for the proportion of ash, and UNE-EN ISO 18123 for volatile matter. Fixed carbon was determined by difference. Ultimate analysis of the feedstock was determined in a Thermo flash 1112, according to UNE EN 5104, and oxygen content was determined by difference. 
Table 1. Feedstock (grapes seeds and polystyrene) characterization.

\begin{tabular}{lccc}
\hline & \multicolumn{2}{c}{ Grape seeds } & Polystyrene \\
\cline { 2 - 4 } & Air-dried basis & Dry & Air-dried basis \\
\hline Ash & 4.3 & 4.6 & 0.3 \\
Volatile matter & 65 & 69.5 & 99 \\
Moisture & 6.3 & $<2$ & 0.5 \\
Fixed Carbon & 24 & 26 & 0.2 \\
& & & \\
Ultimate analysis(wt\%) & & \\
Carbon & 54 & 58 & 91 \\
Hydrogen & 6.6 & 6.3 & 8.8 \\
Nitrogen & 2.2 & 2.4 & 0.0 \\
Sulfur & 0.1 & 0.2 & 0.0 \\
Oxygen & 37 & 34 & 0.3 \\
HHV (MJ/kg) & 22 & 24 & 39 \\
LHV (MJ/kg) & 21 & 22 & 38 \\
\hline HHV: Higher heating value; LHV: Lower heating value; ${ }^{1}:$ By difference
\end{tabular}

\subsection{Thermogravimetric analysis}

The aim of the thermogravimetric analysis was to study the thermal behavior of both feedstocks under pyrolysis conditions. Thus, the thermogravimetric analysis was performed for each feedstock starting at room temperature and rising to $700{ }^{\circ} \mathrm{C}$, at a heating rate of $100{ }^{\circ} \mathrm{C} / \mathrm{min}$ in order to mimic the conditions calculated for the experimental fixed-bed reactor. Solid weight loss and temperature were recorded in a Netzsch Libra F1 Thermobalance. The sample weight used in all experiments was approximately $9 \mathrm{mg}$, and the carrier gas was $\mathrm{N}_{2}(50 \mathrm{Nml} / \mathrm{min})$.

\subsection{Fixed bed reactor}

The pyrolysis process was performed in a stainless steel fixed-bed reactor $(52.5 \mathrm{~cm}$ long and 5 $\mathrm{cm}$ internal diameter), as shown in Figure 1. The reactor was specifically designed to carry out the pyrolysis experiments and featured a vertical mobile piston, where the raw material was introduced to ensure the highest heating rates required for devolatilization. Samples of $35 \mathrm{~g}$ total were pyrolyzed using $\mathrm{N}_{2}$ as the carrier gas $(300 \mathrm{~mL} / \mathrm{min})$. The reactor was heated externally with an electrical resistance of approximately $100^{\circ} \mathrm{C} / \mathrm{min}$ to the final pyrolysis temperature $(550$ ${ }^{\circ} \mathrm{C}$ ). The reaction time needed to guarantee pyrolysis was set at $30 \mathrm{~min}$. A condenser (ice cooled 
trap) with water reflux at $3^{\circ} \mathrm{C}$ was used to collect the condensable fraction of gas. The liquid and solid yields were obtained by weight, while the non-condensable gas yield was calculated from the composition of the gas sampled. Experiments related to conventional pyrolysis of each feedstock were carried out 5 times, maintaining a mass balance of $100 \pm 5 \%$. The product yields of these experiments are compiled in Table S1 and S2 in the Supplementary data. Based on these, several co-pyrolysis experiments were conducted at different proportions of each feedstock: 95Gs/5PS; 90GSs/10PS; 80GSs/20PS and 60GSs/40PS. To ensure a good homogeneity of the feedstock, samples of GSs and PS were carefully mixed prior to introduce the sample into the liner.

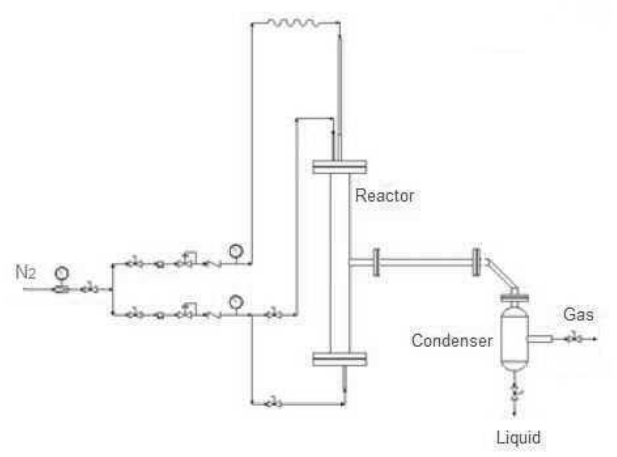

Figure 1. Fixed-bed reactor scheme used for determining co-pyrolysis performance.

\subsection{Product characterization}

After the co-pyrolysis experiments, liquid, solid and gaseous fractions were characterized. The liquid fraction obtained had two distinct phases (organic and aqueous), which had to be separated prior to characterization. For this purpose, the recovered sample was centrifuged at $1500 \mathrm{rpm}$ for 15 minutes and the two liquid layers (aqueous/bottom and organic/top) were collected by decantation. Standard methods were used for an in-depth analysis of the organic liquid phase to determine the physicochemical properties, and a qualitative analysis of the chemical composition was carried out by GC-MS. Pyrolytic bio-oil was also analyzed by means of immediate analysis (Carlo Erba EA1108), calorific value (IKA C- 2000), water content by Karl-Fischer titration (Crison Titromatic) according to ASTM E203-96 and pH (Mettler Toledo 
T50). On the other hand, the qualitative analysis of the chemical composition of the organic phase was conducted using a Varian CP-3800 gas chromatograph connected to a Saturn 2200 ion trap mass spectrometer. A low-bleed capillary column, CP-Sil 8 CB: Phenyl 5\%, dimethylpolysiloxane $95 \%$ (60 m - $0.25 \mathrm{~mm}$ internal diameter, film thickness $0.25 \mu$ ) was used. An initial furnace temperature of $40^{\circ} \mathrm{C}$ was maintained for $4 \mathrm{~min}$. Subsequently, a ramp speed of $4^{\circ} \mathrm{C} /$ min was implemented to reach a final column temperature of $300^{\circ} \mathrm{C}$. This temperature was maintained for $16 \mathrm{~min}$. The carrier gas was He (BIP grade) at a constant column flow of 1 $\mathrm{mL} / \mathrm{min}$. The temperatures of the injector, detector and transfer line were $300^{\circ} \mathrm{C}, 220^{\circ} \mathrm{C}$ and $300^{\circ} \mathrm{C}$, respectively. Sample volumes of $1 \mu \mathrm{l}(1: 25, \%$ by weight, in a mixture of $1: 1$ $\mathrm{CH}_{2} \mathrm{Cl}_{2}: \mathrm{C}_{2} \mathrm{H}_{6} \mathrm{O}$ ) were injected with a split ratio $25: 1$ and a 7.5 min solvent delay. The MS operated in electronic ionization mode with a range of 35-550 m/z. The interpretation of the mass spectra given by the GC-MS analyses was based on the automatic search in the NIST 2011 library. Moreover, a Bruker Vertex 70 spectrometer was used to obtain the Fourier transform infrared spectroscopy (FTIR) spectra of the bio-oil samples. To this end, $50 \mu \mathrm{L}$ of organic liquid samples were deposited on disposable real crystal IR sample cards ( $\mathrm{KBr}$ sample support substrate) with a $15 \mathrm{~mm}$ aperture supplied by International Crystal Laboratories. A Globar source and a deuterated L-alanine-doped triglycine sulfate detector were used for MIR configuration (from 4000 to $400 \mathrm{~cm}^{-1}$ ), and a halogen source and an indium gallium arsenide detector were set up for NIR conditions $\left(9000-4000 \mathrm{~cm}^{-1}\right)$. Each spectrum was acquired in transmission mode using 32 coaveraged scans and a spectral resolution of $2 \mathrm{~cm}^{-1}$. Spectral data were imported from OPUS software and Standard Normal Variate (SNV) was carried out, since this data pretreatment method led to the optimal model performance.

Solid fraction (char) was characterized by measuring its calorific value (IKA C-2000). Noncondensable gases were determined by gas chromatography using an HP Hewlett Packard Series II detector coupled to a TCD detector. The chromatograph was equipped with a Molsieve $5 \AA$ column for $\mathrm{H}_{2}, \mathrm{O}_{2}, \mathrm{~N}_{2}$ and $\mathrm{CO}$ analysis and a HayeSep Q column for $\mathrm{CO}_{2}$ and light hydrocarbons analysis. The two oven programs used were isothermal at $60{ }^{\circ} \mathrm{C}$ and $90{ }^{\circ} \mathrm{C}$ for the 
Molsieve and Hayesep Q columns, respectively. Additionally, higher hydrocarbons were measured through a capillary column in a Varian GC, using a programmed temperature method (isothermal at $60{ }^{\circ} \mathrm{C}$ for 5 minutes and then a heating rate of $20{ }^{\circ} \mathrm{C} / \mathrm{min}$ to $120{ }^{\circ} \mathrm{C}$ maintained at that temperature for 5 minutes). HHV of the non-condensable gas stream was also calculated in $\mathrm{N}_{2}$ free basis from the heating value of each component following the next expression:

$$
H H V=\sum_{i=1}^{n} \frac{\%}{100} * H H V_{i}
$$

Where $\mathrm{HHV}_{\mathrm{i}}$ is the HHV of each component in the gas stream.

\subsection{Synergistic evaluation.}

In order to obtain a better analysis of the impact of the results, theoretical values expected from each property were calculated as an arithmetic sum of the values expected, taking into account that there was no chemical interaction between the two feedstocks during devolatilization. This method has been carried out by several authors [26-29] and can be considered as one of the best approaches to analyze synergistic effects in the properties after any co-pyrolysis process, since bio-oils from lignocellulosic biomass are not miscible in waste polymers oils.

\section{Results and discussion}

\subsection{Thermogravimetric analysis}

Thermogravimetric analysis is a very useful technique to study and understand the behavior of pyrolysis to different feedstocks under well-defined conditions. Thermogravimetric analyses were performed at a heating rate of $100{ }^{\circ} \mathrm{C} / \mathrm{min}$, which was selected as the most representative temperature to carry out the analysis, as the value is in line with the heating rate achieved in the further pyrolysis experiments in the fixed-bed reactor aimed at mimicking the calculated conditions applied in the experimental fixed-bed reactor. The results obtained for weight loss and rate of weight loss for both samples of GSs and PS are given in Figure 2. As it is a type of lignocellulosic biomass, GSs form a complex solid mainly composed of hemicellulose and 
cellulose, which consist of monomeric sugars, and lignin, a complex, cross-linked, threedimensional aromatic polymer made up of phenyl-propane units [30, 31]. Also, minor fractions of extractives, such as fatty acids, simple sugars, waxes and sterols and inorganic mineral matter (inorganic compounds like alkali metals [32], will be present in these samples [33] and can affect the degradation profile [34]. The pyrolysis of biomass normally shows multi-stage reaction patterns that can be briefly explained by the overlapping decomposition of its main components extractives, hemicellulose, cellulose, lignin [35]. At this heating rate, the decomposition pathway of GSs starts at around $200^{\circ} \mathrm{C}$ with the hydrolysis of certain extractives [36] which are less stable and start to degrade at lower temperatures due to their higher volatility $[35,37]$. They then follow the main decomposition of hemicellulose at between $250^{\circ} \mathrm{C}$ and 350 ${ }^{\circ} \mathrm{C}$ [37], and the main devolatilization of the cellulose component at between $350{ }^{\circ} \mathrm{C}$ and $400{ }^{\circ} \mathrm{C}$ [37]. At higher temperatures, decomposition of the strongest bonds in the lignin takes place up to $600{ }^{\circ} \mathrm{C}[34,38]$. Finally, at the higher temperatures, only advanced charring processes continue with a very low reaction rate [37]. The residual weight observed is about $32.1 \mathrm{wt} \%$ and a weight of $36 \mathrm{wt} \%$ at $550{ }^{\circ} \mathrm{C}$ was obtained. The residual mass loss observed is about $67.9 \mathrm{wt} \%$ and a mass loss of $36 \mathrm{wt} \%$ at $550^{\circ} \mathrm{C}$ was obtained.

Regarding PS thermal behavior and according to other research [39, 40], the mass loss tends to occur within a narrow temperature range, since PS can be considered a homogenous material that follows rapid cracking of the PS chain through a single-step process [41]. Thus, PS decomposes at temperatures between $350{ }^{\circ} \mathrm{C}$ to $515{ }^{\circ} \mathrm{C}$, with maximum rate at $462{ }^{\circ} \mathrm{C}$ and a residual weight of about $1.1 \mathrm{wt} \%$, the same weight observed at $550{ }^{\circ} \mathrm{C}$. Comparing GSs and PS devolatilization, it can be seen that there is a remarkably common area where volatile matter coexisted and radical interaction took place. From these results, $550{ }^{\circ} \mathrm{C}$ was deemed the optimum temperature to ensure the total decomposition of both feedstocks. 


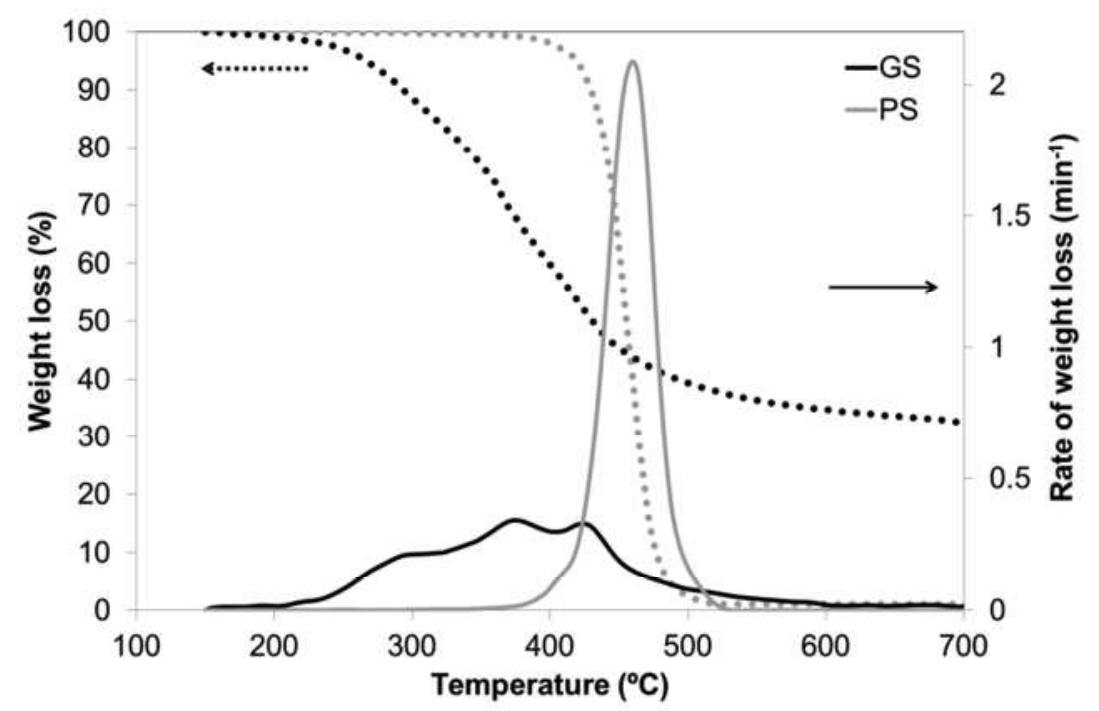

Figure 2. Experimental results of weight loss (dotted lines) and rate of mass loss (solid lines) from the thermogravimetric analyses of grape seeds and waste tyres at $100{ }^{\circ} \mathrm{C} / \mathrm{min}$ heating rate.

\subsection{Influence of PS on product distribution}

In order to analyze the influence from the addition of PS on the product distribution, different mixtures of GSs and PS $(5,10,20,40$, weight percentage) were treated. Firstly, it is worth pointing out that when the GSs and PS samples were pyrolyzed separately, significant differences in yields were observed. Table 2 shows the product distribution obtained from conventional pyrolysis of GSs or PS, where it can be observed that a $39 \mathrm{wt} \%$ of liquid yield was obtained after the GSs pyrolysis, while solid and non-condensable fractions stood at 33 and 24 wt $\%$, respectively. These values show that almost full GSs conversion was achieved since the solid fraction yield was slightly higher than the sum of fixed carbon + ash content obtained by proximate analysis $(31 \mathrm{wt} \%)$, see Table 1 . This product distribution after GSs pyrolysis was similar to that obtained by other authors at a comparable temperature [1], which was designed as the optimum one to maximize the liquid yield. Finally, it is worth commenting that a two-phase distribution was obtained where the organic fraction represented about $60 \mathrm{wt} \%$ of the total liquid. 
On the contrary, PS pyrolysis generated a large liquid fraction of $82 \mathrm{wt} \%$ and a small gas fraction (14 wt\%), while practically no solid fraction was recovered (1 wt \%). Again, these results agreed with those obtained from proximate analysis where the main fraction of PS is volatile matter (99 wt\%). As expected, the liquid fraction consisted of a single organic fraction. These results were in line with those found by other authors, who reported obtaining about 80 $\mathrm{wt} \%$ of liquid fraction, which is the main product from PS pyrolysis [42]. Product yields are remarkably influenced by reactor type and operational conditions, but there is a general consensus that temperatures between $500{ }^{\circ} \mathrm{C}$ to $600{ }^{\circ} \mathrm{C}$ and reaction times ranging from 15 to 45 min are the optimal conditions to ensure the highest liquid yields during PS devolatization [23].

Table 2 also shows the strong influence on product distribution following the addition of PS to the feedstock, which interestingly, increased the liquid yield significantly. As expected from the theory, this effect was more apparent at high PS percentages (20 and $40 \mathrm{wt} \%$ ), where liquid yields over $50 \mathrm{wt} \%$ were obtained. These increments resulted in an improvement of $30 \%$ and $57 \%$, respectively, compared to the liquid obtained from the pyrolysis of GSs on their own. Accordingly, both non-condensable gas and char fraction decreased proportionally. This increment in the liquid phase yield was also evidenced in other research using lignocellulosic biomass and PS as feedstock. Abnisa et al. [23] found that higher percentages of PS in the feedstock resulted in higher liquid yields, whilst gas and solid fractions decreased, with the biomass-to-PS ratio being the most significant variable on the distribution of products. Similar results were obtained by Shadangi et al. [21]. These authors also reported that the largest liquid yields were attained from the highest amounts of PS in the feedstock. Finally, it should be pointed out that, following co-pyrolysis of GSs and PS, a two-phase distribution for the liquid fraction was always obtained, where a homogeneous organic phase could be easily separated after centrifugation. A visual example of the two-phase distribution can be seen at Figure S1 in the Supplementary data. As expected, this fraction increased as the amount of PS was raised, reaching values up to $85 \mathrm{wt} \%$ at the highest percentages of PS (40 wt $\%$ ). For comparative 
purposes, theoretical values obtained from the rule of mixtures are also summarized in Table 2.

It can be observed that liquid yields remained approximately in the same range. On the contrary, a noticeable synergetic effect was observed in the organic fraction yields, since yield values higher than those theoretically expected were attained (10-15\%), demonstrating a remarkable positive effect on this valuable product.

Table 2. Product yields (liquid -organic and aqueous phases-, solid and gas) in wt $\%$ after conventional pyrolysis of GSs and PS and co-pyrolysis of GSs and PS. Values shown represent the mean of 3 experiments.

\begin{tabular}{|c|c|c|c|c|c|c|c|}
\hline & \multicolumn{3}{|l|}{ Feedstock } & \multicolumn{4}{|c|}{ Yields (wt\%) } \\
\hline & \multirow{2}{*}{$\begin{array}{c}\text { GSs/PS } \\
(\mathbf{w t} \%)\end{array}$} & \multicolumn{3}{|c|}{ Liquid } & \multirow{2}{*}{ Solid } & \multirow{2}{*}{$\operatorname{Gas}^{1}$} & \multirow{2}{*}{ Total } \\
\hline & & Total & Org. & Aq. & & & \\
\hline \multirow{3}{*}{$\begin{array}{l}\text { Conventional } \\
\text { pyrolysis }\end{array}$} & $100 / 0$ & $39 \pm 1.2$ & $61 \pm 2.2$ & $39 \pm 1.4$ & $33 \pm 0.3$ & $24 \pm 0.9$ & 96 \\
\hline & $0 / 100$ & $82 \pm 1.1$ & $100 \pm 0.0$ & $0.0 \pm 0.0$ & $1.0 \pm 0.1$ & $14 \pm 0.5$ & 97 \\
\hline & $95 / 5$ & $40 \pm 0.9$ & $74 \pm 1.3$ & $26 \pm 0.5$ & $31 \pm 0.8$ & $26 \pm 0.6$ & 97 \\
\hline \multirow{3}{*}{$\begin{array}{l}\text { Co-pyrolysis of } \\
\text { GSs and PS }\end{array}$} & $90 / 10$ & $42 \pm 0.9$ & $76 \pm 1.4$ & $24 \pm 0.4$ & $31 \pm 0.8$ & $25 \pm 0.5$ & 98 \\
\hline & $80 / 20$ & $51 \pm 1.1$ & $80 \pm 1.4$ & $20 \pm 0.4$ & $27 \pm 0.7$ & $20 \pm 0.4$ & 98 \\
\hline & $60 / 40$ & $62 \pm 1.4$ & $86 \pm 1.5$ & $14 \pm 0.3$ & $21 \pm 0.6$ & $15 \pm 0.3$ & 97 \\
\hline \multirow{4}{*}{$\begin{array}{l}\text { Theoretical co- } \\
\text { pyrolysis of } \\
\text { GSs and PS }\end{array}$} & $95 / 5$ & $41 \pm 0.9$ & $63 \pm 1.1$ & $37 \pm 0.7$ & $32 \pm 0.8$ & $23 \pm 0.5$ & --- \\
\hline & $90 / 10$ & $43 \pm 0.9$ & $65 \pm 1.2$ & $35 \pm 0.6$ & $30 \pm 0.8$ & $23 \pm 0.5$ & --- \\
\hline & $80 / 20$ & $47 \pm 1.0$ & $69 \pm 1.2$ & $31 \pm 0.6$ & $27 \pm 0.7$ & $22 \pm 0.5$ & --- \\
\hline & $60 / 40$ & $56 \pm 1.2$ & $77 \pm 1.4$ & $23 \pm 0.4$ & $20 \pm 0.5$ & $20 \pm 0.4$ & --- \\
\hline
\end{tabular}

Calculated by balance from gas chromatography analysis.

${ }^{2}$ Calculated on the basis of the rule of mixtures from conventional pyrolysis of GSs and PS.

\subsection{The effect of co-pyrolysis of GSs and PS on non-condensable gas distribution}

Table 3 summarizes non-condensable composition after pyrolysis and co-pyrolysis experiments.

As expected, the gas composition of GSs pyrolysis was characterized as a rich $\mathrm{CO}$ and $\mathrm{CO}_{2}$ gas, while the values of $\mathrm{H}_{2}$ and $\mathrm{CH}_{4}$ were also significant. In addition, the calculated heating value for this composition was $15.3 \mathrm{MJ} / \mathrm{Nm}^{3}$.

The non condensable-fraction after PS pyrolysis presented great differences, as it was mainly composed of $\mathrm{H}_{2}, \mathrm{CH}_{4}, \mathrm{C}_{2} \mathrm{H}_{6}$ and $\mathrm{C} 3-\mathrm{C} 4$ hydrocarbons and showed a significant $\mathrm{HHV}$ of 46 $\mathrm{MJ} / \mathrm{kg}$, even higher than natural gas $\left(\sim 39 \mathrm{MJ} / \mathrm{m}^{3}\right)$.

The incorporation of PS into the feedstock had a notable influence on gas composition. It is worth mentioning that, due to the significant differences in gas yields for the various mixtures, results were compared in terms of mass of product per mass of feedstock. $\mathrm{H}_{2}$ slightly increased 
at low PS percentages (5 and $10 \mathrm{wt} \%$ ) compared to the conventional GSs pyrolysis, whereas it decreased at high PS percentages (20 and $40 \mathrm{wt} \%$ ). Surprisingly, at higher percentages, $\mathrm{H}_{2}$ values were significantly lower than those expected from the theory, since $\mathrm{H}_{2}$ yield for PS conventional pyrolysis was remarkably higher. This could be explained by the fact that $\mathrm{H}_{2}$ transfer reactions were likely to be taking place, thus enhancing $\mathrm{H}_{2}$ consumption [43]. Regarding CO composition, it can be highlighted that its presence decreased with higher quantities of PS, while it increased slightly at lower PS ratios (5 and $10 \mathrm{wt} \%$ ). In contrast, the $\mathrm{CO}_{2}$ trend was the same as expected in theory, since it always decreased as the PS percentage was raised in the feedstock. Finally, C2, C3 and C4 hydrocarbons, summarized in the table as higher hydrocarbons, also decreased as the percentage of PS rose, in contrast to the expected tendency. These values were lower than those calculated theoretically since, just as it happened with $\mathrm{H}_{2}$, PS conventional pyrolysis also led to a notable production of $\mathrm{C}_{2}-\mathrm{C}_{4}$ hydrocarbons, mainly $\mathrm{C}_{2} \mathrm{H}_{6}$. This significant reduction of the $\mathrm{C}_{2}-\mathrm{C}_{4}$ hydrocarbons may be associated with the presence of oligomerization reactions generating aromatic compounds, as shown later. As a consequence of this composition, HHV was very little modified for the different PS percentages. A maximum of $19.5 \mathrm{MJ} / \mathrm{Nm}^{3}$ was achieved when the ratio of GSs to PS was 90/10, whilst remaining values stayed in the range of 16 to $18 \mathrm{MJ} / \mathrm{Nm}^{3}$.

Table 3. Non-condensable gases composition after conventional pyrolysis of GSs and PS and copyrolysis of GSs and PS. Gas analysis (g/ $100 \mathrm{~g}$ feed).

\begin{tabular}{|c|c|c|c|c|c|c|c|}
\hline & \multirow{2}{*}{$\begin{array}{c}\text { Experiment } \\
\text { GSs/PS } \\
(\mathbf{w t} \%) \\
\end{array}$} & \multicolumn{6}{|c|}{ Gas analysis (g/ $100 \mathrm{~g}$ feed) } \\
\hline & & $\mathbf{H}_{2}$ & $\mathrm{CO}$ & $\mathrm{CO}_{2}$ & $\mathrm{CH}_{4}$ & $\begin{array}{c}\text { Higher } \\
\text { HCs }\end{array}$ & $\begin{array}{c}\text { HHV } \\
\left(\mathbf{M J} / \mathbf{N m}^{3}\right)\end{array}$ \\
\hline \multirow{3}{*}{$\begin{array}{l}\text { Conventional } \\
\text { pyrolysis }\end{array}$} & $100 / 0$ & 0.3 & 4.8 & 13 & 4.4 & 1.7 & 15 \\
\hline & $0 / 100$ & 0.7 & 0.0 & 0.0 & 1.6 & 12 & 43 \\
\hline & $95 / 5$ & 0.4 & 5.1 & 13 & 5.6 & 2.3 & 18 \\
\hline \multirow{3}{*}{$\begin{array}{l}\text { Co-pyrolysis of GSs } \\
\text { and PSs }\end{array}$} & $90 / 10$ & 0.3 & 4.9 & 12 & 5.6 & 2.5 & 20 \\
\hline & $80 / 20$ & 0.3 & 3.7 & 11 & 4.0 & 1.4 & 17 \\
\hline & $60 / 40$ & 0.2 & 2.7 & 8 & 2.8 & 0.9 & 16 \\
\hline \multirow{4}{*}{$\begin{array}{l}\text { Theoretical co- } \\
\text { pyrolysis of GSs and } \\
\text { WTs }^{1}\end{array}$} & $95 / 5$ & 0.3 & 4.3 & 12 & 4.6 & 2.2 & 17 \\
\hline & $90 / 10$ & 0.3 & 4.1 & 12 & 4.3 & 2.7 & 18 \\
\hline & $80 / 20$ & 0.4 & 3.8 & 10 & 3.9 & 3.8 & 21 \\
\hline & $60 / 40$ & 0.4 & 3.3 & 7.7 & 2.9 & 5.8 & 26 \\
\hline
\end{tabular}

${ }^{1}$ Calculated on the basis of the rule of mixtures from conventional pyrolysis of GSs and PS. 


\subsection{Influence of PS on the properties of liquids and their chemical composition}

Table 4. Elemental analysis, heating value and $\mathrm{pH}$ of the organic layer after conventional pyrolysis of GSs and PS and co-pyrolysis of GSs and PS.

\begin{tabular}{|c|c|c|c|c|c|c|c|c|c|c|}
\hline & \multirow{2}{*}{$\begin{array}{c}\text { Experiment } \\
\text { GSs/PS } \\
(w t \%) \\
\end{array}$} & \multicolumn{7}{|c|}{ Elemental analyses (wt\%) } & \multirow{2}{*}{$\begin{array}{c}\text { HHV } \\
\text { (MJ/kg) }\end{array}$} & \multirow[b]{2}{*}{$\mathbf{p H}$} \\
\hline & & $\mathbf{C}$ & H & $\mathbf{N}$ & $\mathbf{S}$ & $\mathbf{O}^{1}$ & $\mathbf{C} / \mathbf{H}$ & $\mathbf{H} / \mathbf{C}$ & & \\
\hline \multirow{3}{*}{$\begin{array}{l}\text { Conventional } \\
\text { pyrolysis }\end{array}$} & $100 / 0$ & 74 & 9.2 & 2.5 & 0.0 & 14 & 0.7 & 1.5 & 36 & 6.4 \\
\hline & $0 / 100$ & 90 & 7.4 & 2.2 & 0.2 & 0.0 & 1.0 & 1.0 & 41 & 3.8 \\
\hline & $95 / 5$ & 75 & 9.2 & 2.4 & 0.0 & 14 & 0.7 & 1.5 & 36 & 6.2 \\
\hline \multirow{3}{*}{$\begin{array}{l}\text { Co-pyrolysis of } \\
\text { GS and PS }\end{array}$} & $90 / 10$ & 76 & 8.9 & 2.2 & 0.0 & 13 & 0.7 & 1.4 & 37 & 6.1 \\
\hline & $80 / 20$ & 83 & 8.4 & 1.4 & 0.0 & 7.7 & 0.8 & 1.2 & 39 & 5.6 \\
\hline & $60 / 40$ & 85 & 7.9 & 0.9 & 0.0 & 6.3 & 0.9 & 1.1 & 39 & 5.4 \\
\hline \multirow{4}{*}{$\begin{array}{l}\text { Theoretical co- } \\
\text { pyrolysis of GS } \\
\text { and } \mathrm{PS}^{2}\end{array}$} & $95 / 5$ & 75 & 9.3 & 2.4 & 0.0 & 14 & 0.7 & 1.5 & 37 & 6.3 \\
\hline & $90 / 10$ & 75 & 9.4 & 2.3 & 0.1 & 13 & 0.7 & 1.5 & 37 & 6.1 \\
\hline & $80 / 20$ & 78 & 9.5 & 2.1 & 0.1 & 11 & 0.8 & 1.4 & 38 & 5.9 \\
\hline & $60 / 40$ & 80 & 9.8 & 1.7 & 0.2 & 8.6 & 0.8 & 1.3 & 38 & 5.4 \\
\hline
\end{tabular}

${ }^{2}$ Calculated on the basis of the rule of mixtures from conventional pyrolysis of GSs and PS.

$\mathrm{H} / \mathrm{C}$ and $\mathrm{C} / \mathrm{H}$ represent atomic ratio

After centrifugation and separation of the liquid fraction, several physicochemical properties of the organic phase were determined. Table 4 shows the elemental analysis and heating value of the samples, two of the main indicators of the quality of the bio-oil. As can be seen, the organic fraction obtained from GSs pyrolysis was characterized by a relatively high oxygen content (14.3 wt\%) and a remarkable HHV (36.0 MJ/kg). Conversely, the oil obtained from PS pyrolysis was shown to be an oxygen-free fraction containing a significant carbon content. This composition gave rise to a greater HHV of $40.8 \mathrm{MJ} / \mathrm{kg}$, similar to that of commercial liquid fuels, such as gasoline or diesel [44]. From these results and as expected, the addition of PS to the feedstock reduced the oxygen content in the organic fraction whilst $\mathrm{C}$ content increased, leading to higher HHV. At low percentages of PS, 5 and $10 \mathrm{wt} \%$, the oxygen content decreased as expected (similar values to those calculated theoretically). The deoxygenation rates were higher with larger amounts of PS (20 and $40 \mathrm{wt} \%$ ), which reduced oxygen content to 7.7 and $6.3 \mathrm{wt} \%$, respectively. These values represent deoxygenation rates of $46 \%$ and $56 \%$, correspondingly. These values were greater than those expected in theory, leading to the conclusion that positive synergistic effects arose when high percentages of PS were added to the pyrolysis of GSs. In line with this, lower $\mathrm{H} / \mathrm{C}$ ratio values were obtained as the PS percentage 
was increased, always being closer to 1 than those calculated theoretically. This fact demonstrates that the addition of PS to the GSs feedstock synergistically promotes the formation of aromatic compounds [45]. These results agreed with the literature [7, 14, 46] where it was demonstrated that PS incorporation into lignocellulosic biomass improved the quality of the upgraded bio-oil, due to transformation of oxygenated compounds into aromatic compounds.

Table 4 also shows the bio-oil $\mathrm{pH}$ values, an indicator of the potential corrosion problems which it can cause. It can be also observed in Table 4 that $\mathrm{pH}$ values of GSs and PS oils were 6.4 and 3.8, respectively, emphasizing the more acidic character from conventional PS pyrolysis compared to that obtained from GSs. Fortunately, after co-pyrolysis processes, $\mathrm{pH}$ values remained in the range of 5.4-6.2, as expected from the theory, values that should prevent the significant issues linked to handling and storage of these bio-oils $[12,13]$. At this stage, it must be pointed out that a negligible amount of water was found in the organic fraction, always achieving values lower than $1 \mathrm{wt} \%$, suggesting that most of the water-soluble components were condensed in the aqueous phase.

To complete the physicochemical characterization of the organic fraction, a qualitative GC-MS analysis was performed. Figure 3, shows the chromatograms obtained from the organic layer after conventional pyrolysis of GSs and PS, and following co-pyrolysis. Considering this Figure should be evaluated as a qualitative trend, it can be observed that chemical composition of the organic fraction obtained from pyrolysis of GSs and PS were completely different. The main components of the organic fraction after GSs pyrolysis comprised a mixture of a predominant fraction consisting mainly of phenols and other oxygenated compounds, such as fatty acids methyl esters (FAME) and a smaller fraction of various oxygenated compounds, such as esters, ketones or aldehydes that were not included as individual compounds in the chromatogram for the sake of clarity and simplicity. In any case, to provide more in-depth information, all individual components detected in the liquids, together with their retention time, are summarized in the supplementary data (See Table S3, S4 and S5). These components have also 
been identified in other studies focusing on the thermal degradation of GSs [38]. Conversely, the oil produced from pyrolysis of PS mostly consisted of aromatics and styrene-derived compounds. Indeed, the main components in the liquid were styrene, its dimer and trimer, toluene and ethyl-benzene. As several researchers have reported, these components are the principal ones remaining after PS pyrolysis [20, 24, 42, 47], with styrene being the major compound. Styrene monomers are usually produced through $\beta$-scission of $\mathrm{C}-\mathrm{C}$ bonds of PS in the main chain [22].

As shown in Figure 3, the addition of PS to the pyrolysis of GSs led to a liquid with a different chemical nature. It can be seen that, as PS increased in the feedstock, it was possible to produce an aromatic-rich bio-oil in which the production of phenols and other oxygenates, especially fatty acids and other oxygenated compounds, disappeared to a great extent. As expected from the theory, the production of aromatics and decrease in oxygenated compounds could be attributed to the inherent chemical structure of PS [48]. Thus, one of the main objectives, which was to reduce the complex nature of the lignocellulosic-derived bio-oils, can be achieved through this one-step process, especially when PS represents 20 or $40 \mathrm{wt} \%$ in the feedstock. The effect on chemical composition of the liquid after the addition of PS corresponded with the studies conducted by other authors with other types of lignocellulosic biomass. In line with this, Pinto et al. [49] concluded that co-pyrolysis of PS and rice crop wastes led to a higher yield of aromatic hydrocarbons in the final liquid. Likewise, Shadangi et al. [21] found that using a karanja and niger seeds-to-PS ratio of 2, the resulting bio-oil mainly consisted of aromatics such as benzene, toluene and styrene, and a small group of oxygenates such as esters and acids. Similarly, Dorado et al. [28] found that aromatics, and especially styrene and ethylbenzene, were synergistically improved after the co-pyrolysis of PS with either biomass model components (cellulose or lignin) or lignocellulosic biomass (switch grass). 


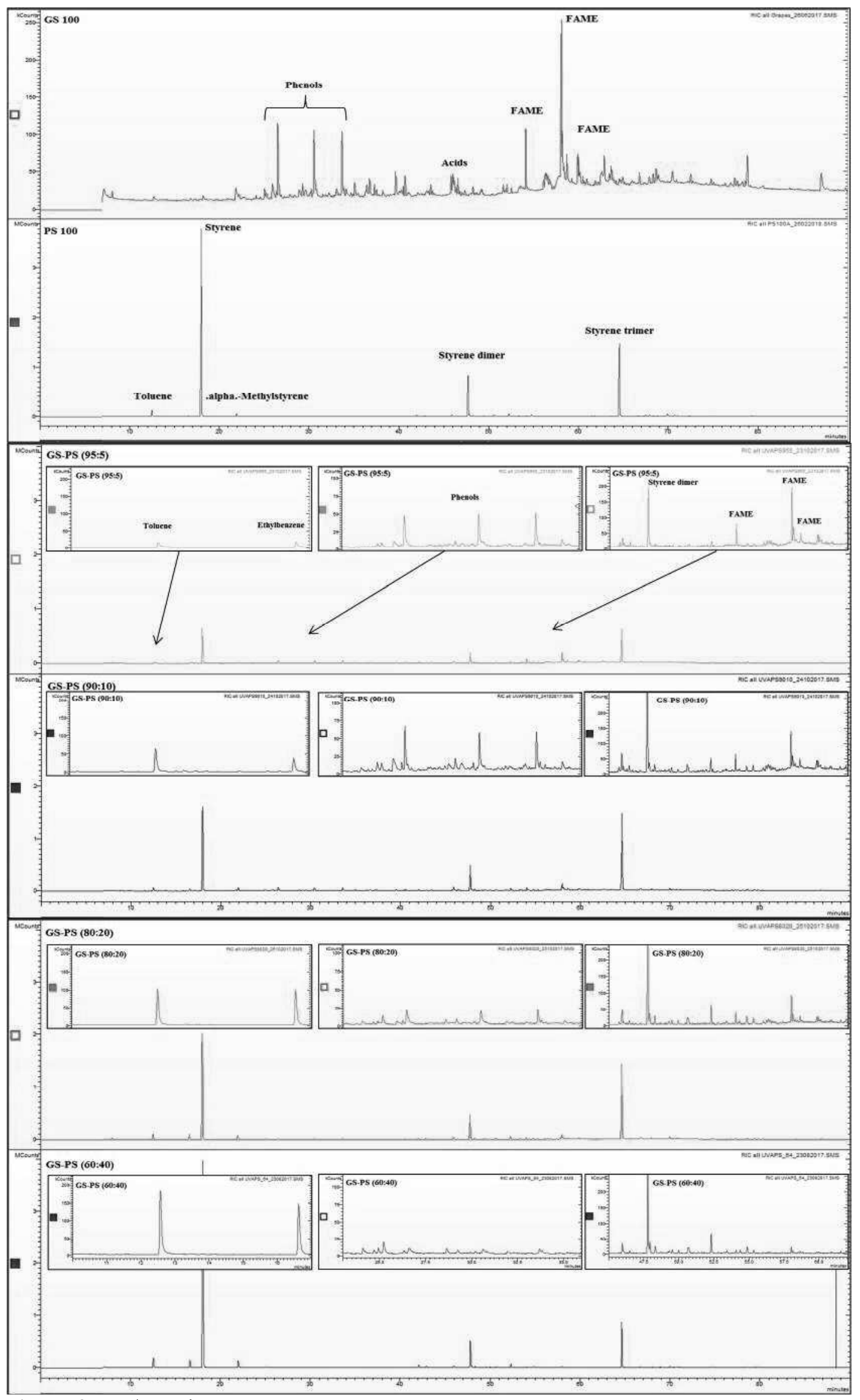

Figure 3. GC/MS chromatograms after conventional pyrolysis of GSs and PS and co-pyrolysis of GSs and PS. 

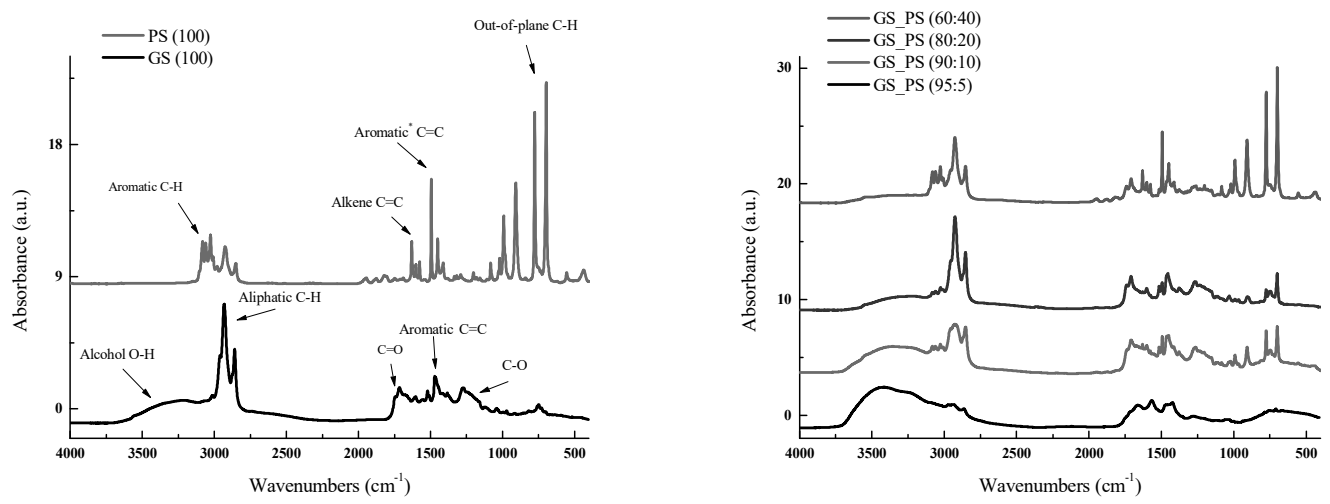

*Strong band at $1493 \mathrm{~cm}^{-1}$ in polystyrene

Figure 4. Infrared spectra with SNV spectral treatment of organic fraction from pyrolysis of PS and GSs (left) and organic fraction from co-pyrolysis of GSs and PS of different blends (right).

FTIR spectra of the organic fraction samples were also carried out. As can be seen in Figure 4, both liquids from pyrolysis of GSs and PS exhibited a completely different spectrum. Regarding the FTIR spectra from liquid of pyrolysis of GSs, the broad band covering the range 3100-3600 $\mathrm{cm}^{-1}$ associated with $\mathrm{O}-\mathrm{H}$ groups is worth noting, as it would indicate the presence of phenols. In addition, singular bands in the region between $1800-1100 \mathrm{~cm}^{-1}$, belonging to the $\mathrm{C}=\mathrm{O}$ and $\mathrm{C}$ $\mathrm{O}$ stretching, related to esters, carboxylic and fatty acids or ketones and $\mathrm{C}=\mathrm{C}$ stretching related to the presence of aromatics, were also in evidence. Interestingly, there were almost no strong bands indicating C-H vibrations from alkane hydrocarbons, except for those at 2925 and 2854 $\mathrm{cm}^{-1}$.

With regard to the PS liquid spectra, the presence of aromatic $\mathrm{C}-\mathrm{H}$ and $\mathrm{C}=\mathrm{C}$ bonds was reflected across the spectral region. The region of the $\mathrm{C}-\mathrm{H}$ stretching modes associated with mononuclear aromatic hydrocarbons was seen at 3027, 3060 and $3082 \mathrm{~cm}^{-1}$. Bands at 2924 and $2849 \mathrm{~cm}^{-1}$ corresponded to asymmetric and symmetric stretching vibrations of methylene groups $-\mathrm{CH}_{2}$. Interestingly, similar results to the ones reported in this paper for polystyrene IR spectrum have been published by other authors [41, 50]. Bands at 1629,1600 and $1576 \mathrm{~cm}^{-1}$ reflected the contribution of $\mathrm{C}=\mathrm{C}$ aromatic and alkene hydrocarbons. An intense band at $1494 \mathrm{~cm}^{-1}$ and another weaker one at $1449 \mathrm{~cm}^{-1}$ were characteristic of polystyrene and also indicated the carbon-carbon stretching vibrations in the aromatic ring [50]. This band at $1449 \mathrm{~cm}^{-1}$ may be 
attributed to both the ring breathing of the benzene ring and the deformation vibration of $-\mathrm{CH}_{2}$ [51]. 600-936 $\mathrm{cm}^{-1}$ was the region of special interest in the PS spectrum, where several strong bands appeared indicating out-of-plane $\mathrm{C}-\mathrm{H}$ vibrations, which is characteristic of the aromatic substitution pattern with intense bands at 697 and $776 \mathrm{~cm}^{-1}$ [50]. In fact, there is a general consensus on the characteristic spectrum region in the range between 1000 and $500 \mathrm{~cm}^{-1}$ being linked to the presence of styrene monomers [41].

Figure 4 also shows the different FTIR spectra after co-pyrolysis. The spectra of the pyrolysis oils for the different blends of GSs and PS showed that the characteristic bands evolved as the percentage of PS in the blend was increased. At lower percentages of PS ( $5 \mathrm{wt} \%)$, the spectrum was more similar to the one for GSs oils where a predominance of $\mathrm{O}-\mathrm{H}$ groups, $\mathrm{C}=\mathrm{O}$ and $\mathrm{C}-\mathrm{O}$ vibrations related to alcohols, carboxylic or fatty acids and esters were seen. In fact, the absence of particularly intense bands at around $1000-500 \mathrm{~cm}^{-1}$, characteristic of PS liquid, was remarkable. As the PS percentage increased, the spectrum observed became more similar to the one obtained for the liquid from PS. Thus, the aromatic $\mathrm{C}-\mathrm{H}$ vibrations at wave numbers higher than $3000 \mathrm{~cm}^{-1}$ and the strong bands corresponding to the aromatic $\mathrm{C}=\mathrm{C}$ and out-of-plane $\mathrm{C}-\mathrm{H}$ vibrations increased with larger amounts of PS. This agrees with the results obtained by GCMS, where the same effect of PS enhancing aromatic compounds (mainly related to toluene, ethyl benzene and styrene-derived compounds) was observed in the final liquid fraction.

Regarding the characterization following the simultaneous GC-MS and FTIR technique, it can be stated that this combination is an effective qualitative measurement method for co-pyrolysis processes that include liquids of a complex nature. Just as GC-MS analysis is valuable in determining the existence of the species and mutual interactions among the lignocellulosic and aromatic fractions of PS, so FTIR gives important information about the functional groups. 


\section{Co-pyrolysis of GSs and PS: Overview of the suggested reaction mechanism}

Since $\mathrm{CO}$ and $\mathrm{CO}_{2}$ were the main components in the gas fraction after biomass pyrolysis, but not present after PS pyrolysis, $\mathrm{CO}$ and $\mathrm{CO}_{2}$ production were calculated taking into account only the biomass feedstock in each experiment to obtain a better approach. Figure 5 shows that $\mathrm{CO}$ stayed at higher values than those expected from the theory, and increased with larger amounts of PS in the feedstock Accordingly, it could be stated that decarbonylation reactions played an important role in bio-oil deoxygenation. Similarly, decarboxylation reactions could also play a fundamental role in bio-oil deoxygenation since $\mathrm{CO}_{2}$ production was significantly increased above theoretical values, as can be seen in Figure 5. In particular, this seems to be boosted synergistically with higher amounts of PS in the feedstock. The latter could be directly related to the promotion of decarboxylation reactions of fatty acids, as suggested by the reduction in these components observed through GC-MS and FTIR spectra.
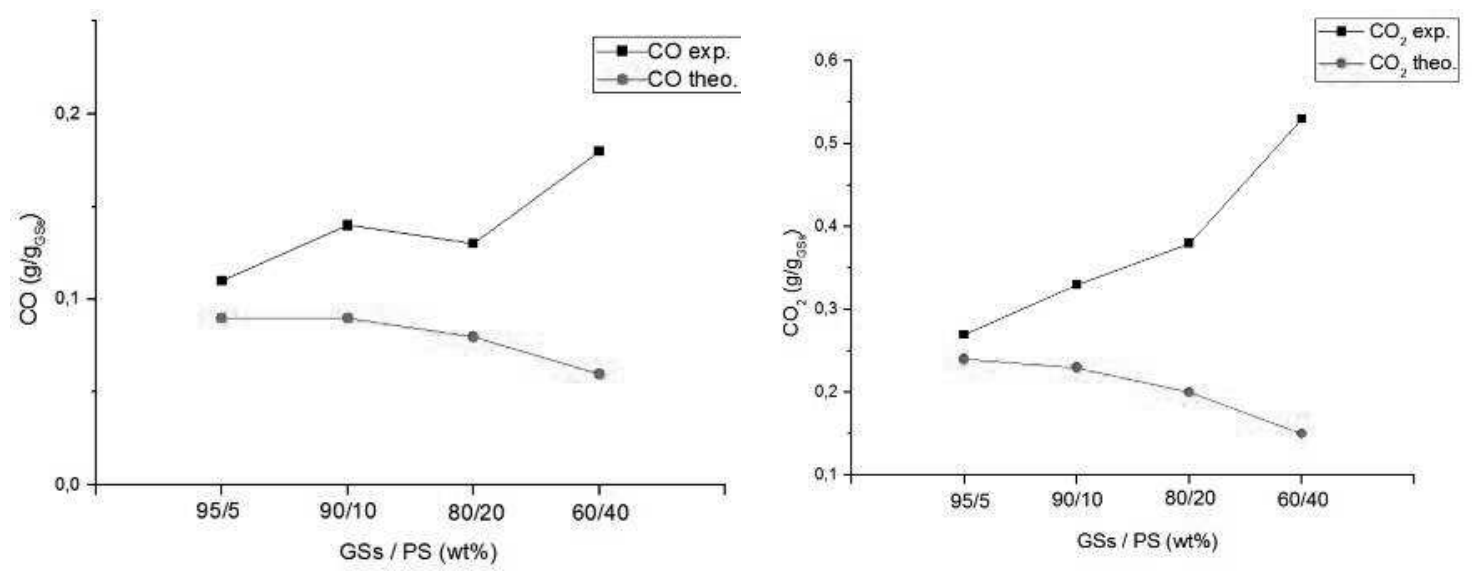

Figure 5. Evolution of $\mathrm{CO}$ and $\mathrm{CO}_{2}\left(\mathrm{~g} / \mathrm{g}_{\mathrm{GSs}}\right.$ feed $)$ production in the co-pyrolysis of GSs and PS.

On the other hand, and as expected, the thermal scission of PS chains should provide extra $\mathrm{H}_{2}$ production, which seems to be consumed as the amount of PS increases, as outlined in Figure 6, where theoretical $\mathrm{H}_{2}$ production should be noticeably higher than those values obtained from experiments, especially at higher amounts of PS. This could be strongly related with the hydrodeoxygenation of phenol compounds to form aromatic hydrocarbons, a trend demonstrated in the previous section. In line with this, and as observed in other studies, the addition of PS to biomass pyrolysis significantly decreased the bio-oil content in phenolic 
compounds [40]. Likewise, positive synergistic effects on reducing phenolic composition were reported by Hassan et al. [22] during co-pyrolysis of torrefied wood and PS (biomass-to-PS ratio of 4). Thus, these results suggest that several oxygenated compounds presented in the organic fraction of GSs may be completely hydrodeoxygenated and transformed into desired compounds, due to extra production of $\mathrm{H}_{2}$ [52]. Interestingly, these reactions seem to be enhanced as the amount of PS was increased in the feedstock.

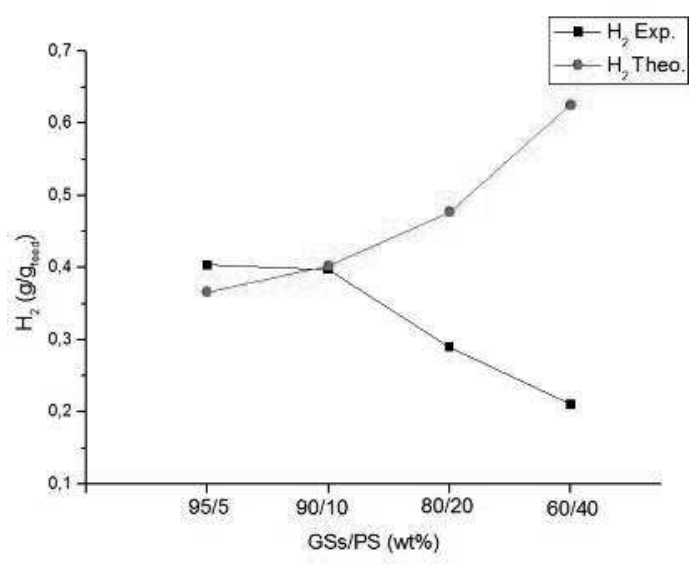

Figure 6. Evolution of $\mathrm{H}_{2}$ production in the co-pyrolysis of GSs and PS.

A simplified overview of the suggested mechanism reaction for the co-pyrolysis of GSs and PS is summarized in Figure 5. Regarding GSs pyrolysis, fatty acids, indicative components of GSs [38], would be transformed into long-chain hydrocarbons through dehydration, decarbonylation, and decarboxylation reactions. From thermal degradation of cellulose and hemicellulose, mainly esters, ketones and other oxygenated compounds are formed through decarbonylation and decarboxylation reactions $[31,53]$. The degradation of lignin would be the main source of phenols, as these compounds can be considered the main products after lignin devolatilisation $[31,53-55]$. On the other hand, the thermal degradation of PS entails two main routes that would take place at the same time, as other authors have proposed [24]. Since the random scission mechanism provides mostly styrene-derived compounds, the chain-end scission mechanism would produce $\mathrm{H}_{2}$ and free radicals that are transformed into straight chain hydrocarbons via hydrogen transfer reactions, with these products being essential for deoxygenation and to produce the desired compounds. 


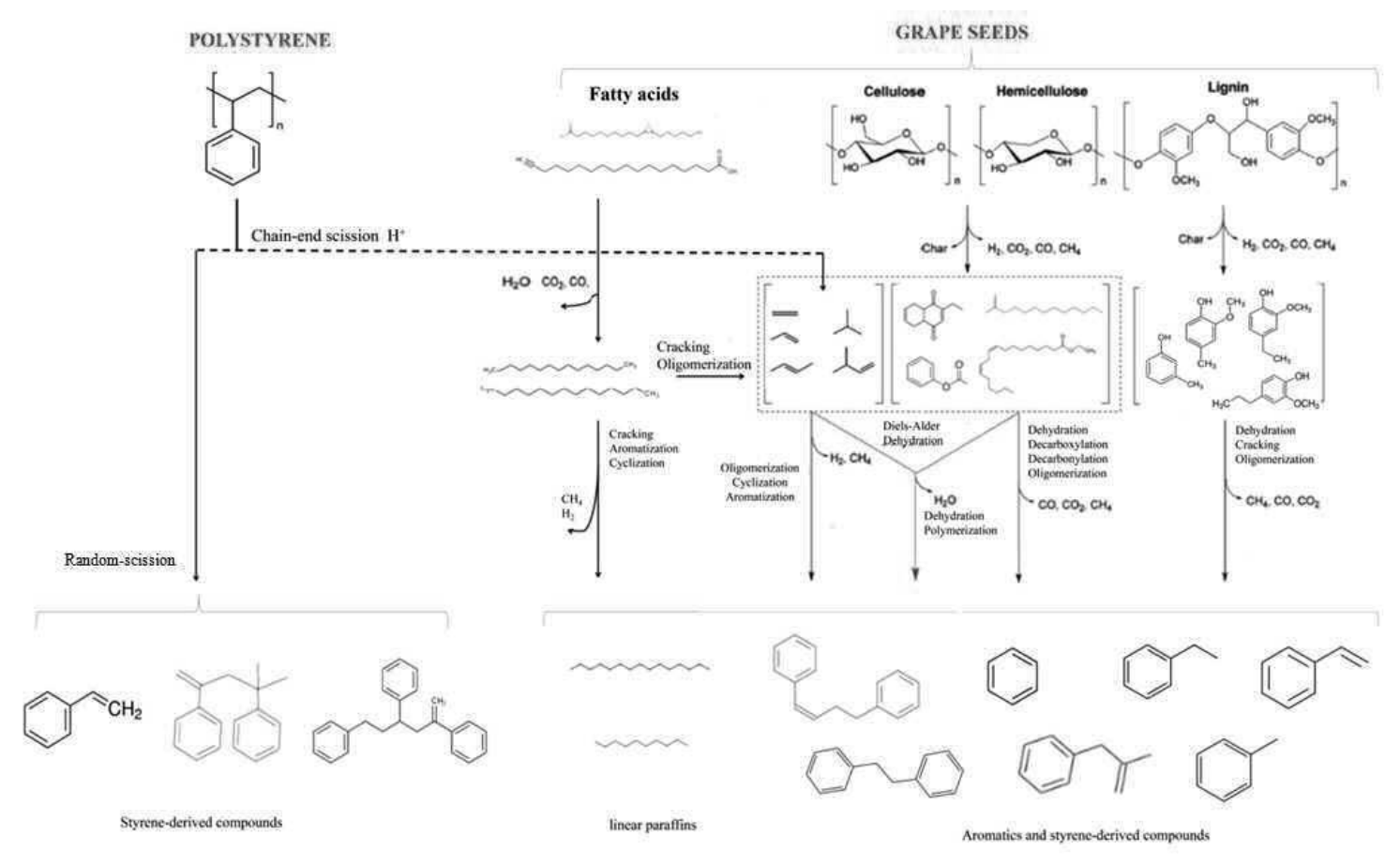

Figure 7. Simplified reaction mechanism proposed for the co-pyrolysis of GSs and PS [24, 56]. showing the main components after the pyrolysis of GSs and the co-pyrolysis of GSs and PS.

\subsection{Potential application as a drop-in fuel.}

In order to accept this liquid as a potential drop-in fuel and to check the improvements achieved after the process, different mixtures of the bio-oil with gasoline and diesel were proposed. Fortunately, the new chemical composition obtained by adding large amounts of PS in the feedstock (20 and $40 \mathrm{wt} \%$ ) makes the bio-oil compatible with current commercial fuels. Thus, as seen in Figure 6, and after a simple filtering step recommended by other authors [57], the resulting drop-in fuel could be used directly as a homogeneous liquid fuel.

These results have shown the great potential of this product to be used as a fuel in the present infrastructures, however there is still some challenges to accomplish in order to ensure an economic and technical application of these biofuels. For that, the scale up of this process together to the possibility of using this mixture in automotive diesel or gasoline engines are the next steps for the development of new advanced biofuels. 
In this regard, several tests performed in a continuous auger reactor on pilot scale are in progress. Then, the application of the mixtures of the resulting bio-oil together with diesel or gasoline in present automotive engines could provide the necessary insights for the application of second generation bio-oils from co-pyrolysis of GSs and PS. For that, based on previous experiences in the field [58] several test have been proposed based on the measurement of the specific fuel consumption, combustion duration and brake thermal efficiency at both low and high engine loads. In addition, controlling the total HCs, NOx and particulate matter emissions have been fixed as one of the main targets of the proposed future work .
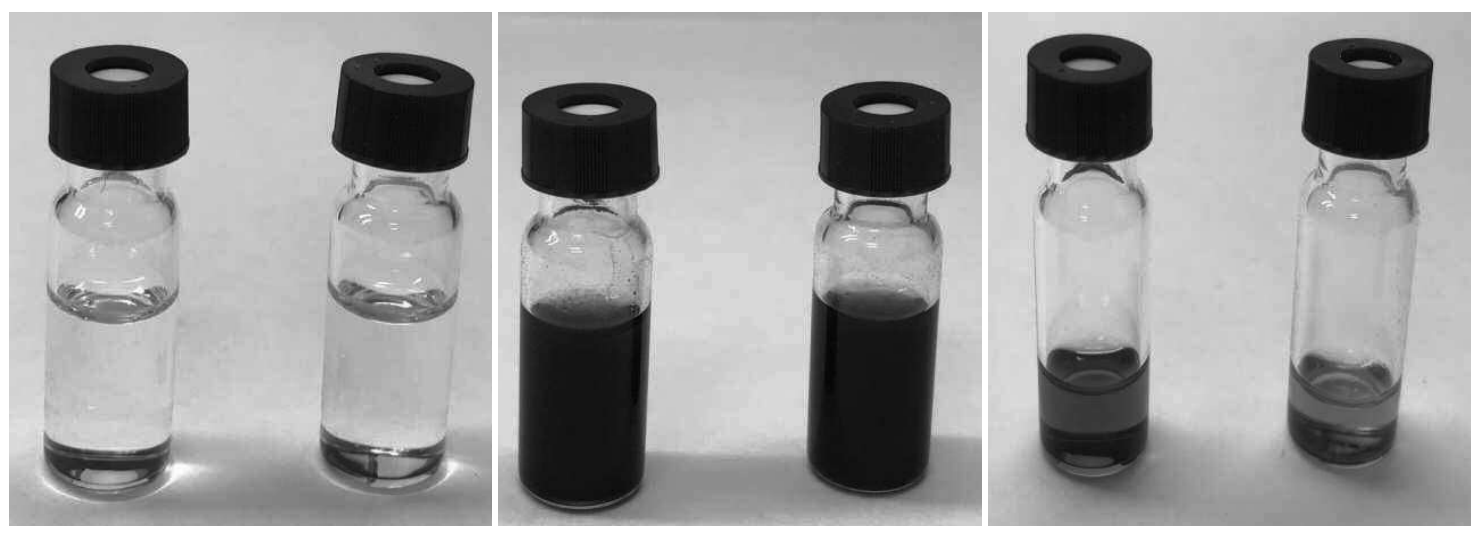

Figure 6. From left to right: (1) Gasoline and diesel. (2) Mixture gasoline and diesel with biooil (5 Vol\%) obtained after co-pyrolysis of GSs and PS (80/20 wt $\% / \mathrm{wt} \%$ ). (3) Mixture gasoline and diesel with bio-oil (5 Vol\%) obtained after co-pyrolysis of GSs and PS (80/20 wt $\% / \mathrm{wt} \%)$ after filtering process.

\section{Conclusions}

In this research, the co-pyrolysis of GSs and PS was successfully conducted in a fixed-bed reactor designed for the purpose. The results exhibited the potential of GSs and PS for use in copyrolysis. Thus, the organic phase yield of the bio-oil was considerably improved after the addition of PS, reaching values over $80 \mathrm{wt} \%$, significantly higher than those obtained from conventional pyrolysis of GSs (61 wt\%). Moreover, meaningful positive synergistic effects were found by decreasing oxygen content and increasing the heating value. In addition, a slightly acid bio-oil was obtained with $\mathrm{pH}$ values ranging from 5.4 to 6.2 , thus reducing the issues associated with handling bio-oils from pyrolysis of lignocellulosic biomass. Finally, a 
large increment of the desired compounds, mainly aromatic hydrocarbons was also achieved, together with a low content of undesired compounds such as phenols. Thus, it was demonstrated that PS could act as an $\mathrm{H}_{2}$ donor, favoring oligomerization, cyclation and hydrodeoxygenation reactions into aromatic hydrocarbons. The results showed that simultaneous GC-MS and FTIR can be used as an effective method for qualitative measurement for co-pyrolysis processes involving liquids with a complex chemical nature.

\section{Acknowledgements}

The authors would like to thank MINECO and FEDER for their financial support (Project ENE2015-68320-R). O.S.P acknowledges the FPI fellowship (BES-2016-077750) funded by MINECO. The authors would also like to thank the Regional Government of Aragon (DGA) for the support provided under the research groups support programme.

\section{References}

1. $\mathrm{Xu}, \mathrm{R}$., et al., Flash pyrolysis of grape residues into biofuel in a bubbling fluid bed. Journal of Analytical and Applied Pyrolysis, 2009. 86(1): p. 58-65.

2. Situation Report for the World Vitivinicultural Sector in 2005, International Organization of Vine and Wine, http://www.oiv.int/.

3. Dwyer, K., F. Hosseinian, and M. Rod, The Market Potential of Grape Waste Alternatives. Vol. 3. 2014. 91-106.

4. $\mathrm{Yu}, \mathrm{J}$. and M. Ahmedna, Functional components of grape pomace: their composition, biological properties and potential applications. International Journal of Food Science \& Technology, 2013. 48(2): p. 221-237.

5. Bustamante, M.A., et al., Agrochemical characterisation of the solid by-products and residues from the winery and distillery industry. Waste Management, 2008. 28(2): p. 372-380.

6. Chand, R., et al., Grape waste as a biosorbent for removing $\mathrm{Cr}(\mathrm{VI})$ from aqueous solution. Journal of Hazardous Materials, 2009. 163(1): p. 245-250.

7. Uzoejinwa, B.B., et al., Co-pyrolysis of biomass and waste plastics as a thermochemical conversion technology for high-grade biofuel production: Recent progress and future directions elsewhere worldwide. Energy Conversion and Management, 2018. 163: p. 468-492.

8. Stefanidis, S.D., K.G. Kalogiannis, and A.A. Lappas, Co-processing bio-oil in the refinery for drop-in biofuels via fluid catalytic cracking. WIREs Energy and Environmental, 2017. e281. 
9. Gamliel, D.P., G.M. Bollas, and J.A. Valla, Two-stage catalytic fast hydropyrolysis of biomass for the production of drop-in biofuel. Fuel, 2018. 216: p. 160-170.

10. Yildiz, G., et al., Challenges in the design and operation of processes for catalytic fast pyrolysis of woody biomass. Renewable and Sustainable Energy Reviews, 2016. 57: p. 1596-1610.

11. Brown, J.N. and R.C. Brown, Process optimization of an auger pyrolyzer with heat carrier using response surface methodology. Bioresource Technology, 2012. 103(1): p. 405-414.

12. Oasmaa, A. and C. Peacocke, A guide to physical property characterisation of biomassderived fast pyrolysis liquids, in VTT Publications. 2001. p. 2-65.

13. Bridgwater, A.V., Biomass fast pyrolysis. Therm. Sci., 2004. 8(2): p. 21-49.

14. Abnisa, F. and W.M.A. Wan Daud, A review on co-pyrolysis of biomass: An optional technique to obtain a high-grade pyrolysis oil. Energy Conversion and Management, 2014. 87: p. 71-85.

15. Demirbas, A., Pyrolysis of municipal plastic wastes for recovery of gasoline-range hydrocarbons. Journal of Analytical and Applied Pyrolysis, 2004. 72(1): p. 97-102.

16. Mahalik, N.P. and A.N. Nambiar, Trends in food packaging and manufacturing systems and technology. Trends in Food Science \& Technology, 2010. 21(3): p. 117-128.

17. Buekens, A.G. and H. Huang, Catalytic plastics cracking for recovery of gasoline-range hydrocarbons from municipal plastic wastes. Resources, Conservation and Recycling, 1998. 23(3): p. 163-181.

18. Miskolczi, N., et al., Thermal degradation of municipal plastic waste for production of fuel-like hydrocarbons. Polymer Degradation and Stability, 2004. 86(2): p. 357-366.

19. Anuar Sharuddin, S.D., et al., A review on pyrolysis of plastic wastes. Energy Conversion and Management, 2016. 115: p. 308-326.

20. L. Gurman, J., L. Baier, and B. C. Levin, Polystyrenes: A Review of the Literature on the Products of Thermal Decomposition and Toxicity. Vol. 11. 1987. 109-130.

21. Shadangi, K.P. and K. Mohanty, Co-pyrolysis of Karanja and Niger seeds with waste polystyrene to produce liquid fuel. Fuel, 2015. 153: p. 492-498.

22. Hassan, E.B., I. Elsayed, and A. Eseyin, Production high yields of aromatic hydrocarbons through catalytic fast pyrolysis of torrefied wood and polystyrene. Fuel, 2016. 174: p. 317-324.

23. Abnisa, F., et al., Co-pyrolysis of palm shell and polystyrene waste mixtures to synthesis liquid fuel. Fuel, 2013. 108: p. 311-318.

24. Zhang, X., et al., Catalytic co-pyrolysis of lignocellulosic biomass with polymers: A critical review. Green Chemistry, 2016. 18(15): p. 4145-4169.

25. Vassilev, S.V., et al., An overview of the chemical composition of biomass. Fuel, 2010. 89(5): p. 913-933.

26. Cao, Q., et al., Investigations into the characteristics of oils produced from co-pyrolysis of biomass and tire. Fuel Processing Technology, 2009. 90(3): p. 337-342.

27. Martínez, J.D., et al., Co-pyrolysis of biomass with waste tyres: Upgrading of liquid biofuel. Fuel Processing Technology, 2014. 119: p. 263-271.

28. Dorado, C., C.A. Mullen, and A.A. Boateng, H-ZSM5 catalyzed co-pyrolysis of biomass and plastics. ACS Sustainable Chemistry and Engineering, 2014. 2(2): p. 301-311.

29. Sanahuja-Parejo, O., et al., Catalytic co-pyrolysis of grape seeds and waste tyres for the production of drop-in biofuels. Energy Conversion and Management, 2018. 171: p. 1202-1212.

30. Cabeza, A., et al., Autocatalytic kinetic model for thermogravimetric analysis and composition estimation of biomass and polymeric fractions. Fuel, 2015. 148: p. 212225.

31. Wang, S., et al., Lignocellulosic biomass pyrolysis mechanism: A state-of-the-art review. Progress in Energy and Combustion Science, 2017. 62: p. 33-86. 
32. Sharma, A., V. Pareek, and D. Zhang, Biomass pyrolysis-A review of modelling, process parameters and catalytic studies. Renewable and Sustainable Energy Reviews, 2015. 50: p. 1081-1096.

33. Kan, T., V. Strezov, and T.J. Evans, Lignocellulosic biomass pyrolysis: A review of product properties and effects of pyrolysis parameters. Renewable and Sustainable Energy Reviews, 2016. 57: p. 1126-1140.

34. Özsin, G. and A.E. Pütün, Kinetics and evolved gas analysis for pyrolysis of food processing wastes using TGA/MS/FT-IR. Waste Management, 2017. 64: p. 315-326.

35. Shebani, A.N., A.J. van Reenen, and M. Meincken, The effect of wood extractives on the thermal stability of different wood species. Thermochimica Acta, 2008. 471(1): p. 4350.

36. White, J.E., W.J. Catallo, and B.L. Legendre, Biomass pyrolysis kinetics: A comparative critical review with relevant agricultural residue case studies. Journal of Analytical and Applied Pyrolysis, 2011. 91(1): p. 1-33.

37. Părpăriţă, E., et al., Pyrolysis behaviors of various biomasses. Polymer Degradation and Stability, 2014. 100: p. 1-9.

38. Brebu, M., et al., Thermal and catalytic degradation of grape seeds/polyethylene waste mixture. Vol. 48. 2014. 665-674.

39. Oyedun, A.O., et al., Mixed-waste pyrolysis of biomass and plastics waste - A modelling approach to reduce energy usage. Energy, 2014. 75: p. 127-135.

40. Faisal, A., D.W.M.A. Wan, and S. J.N., Pyrolysis of mixtures of palm shell and polystyrene: An optional method to produce a high-grade of pyrolysis oil. Environmental Progress \& Sustainable Energy, 2014. 33(3): p. 1026-1033.

41. Özsin, G. and A.E. Pütün, Insights into pyrolysis and co-pyrolysis of biomass and polystyrene: Thermochemical behaviors, kinetics and evolved gas analysis. Energy Conversion and Management, 2017. 149: p. 675-685.

42. Miandad, R., et al., Influence of temperature and reaction time on the conversion of polystyrene waste to pyrolysis liquid oil. Waste Management, 2016. 58: p. 250-259.

43. Ahmed, I.I. and A.K. Gupta, Hydrogen production from polystyrene pyrolysis and gasification: Characteristics and kinetics. International Journal of Hydrogen Energy, 2009. 34(15): p. 6253-6264.

44. Perkins, G., T. Bhaskar, and M. Konarova, Process development status of fast pyrolysis technologies for the manufacture of renewable transport fuels from biomass. Renewable and Sustainable Energy Reviews, 2018. 90: p. 292-315.

45. Yue, L., et al., Impacts of hydrogen to carbon ratio $(\mathrm{H} / \mathrm{C})$ on fundamental properties and supercritical cracking performance of hydrocarbon fuels. Chemical Engineering Journal, 2016. 283: p. 1216-1223.

46. Suriapparao, D.V., et al., Microwave assisted co-pyrolysis of biomasses with polypropylene and polystyrene for high quality bio-oil production. Fuel Processing Technology, 2018. 175: p. 64-75.

47. Artetxe, M., et al., Styrene recovery from polystyrene by flash pyrolysis in a conical spouted bed reactor. Waste Management, 2015. 45: p. 126-133.

48. Zhang, H., et al., Catalytic Co-pyrolysis of Biomass and Different Plastics (Polyethylene, Polypropylene, and Polystyrene) To Improve Hydrocarbon Yield in a Fluidized-Bed Reactor. Energy \& Fuels, 2014. 28(3): p. 1940-1947.

49. Pinto, F., M. Miranda, and P. Costa, Production of liquid hydrocarbons from rice crop wastes mixtures by co-pyrolysis and co-hydropyrolysis. Fuel, 2016. 174: p. 153-163.

50. Olmos, D., E.V. Martin, and J. Gonzalez-Benito, New molecular-scale information on polystyrene dynamics in PS and PS-BaTiO3 composites from FTIR spectroscopy. Physical Chemistry Chemical Physics, 2014. 16(44): p. 24339-24349. 
51. Guangming, C., et al., FTIR Spectra, Thermal Properties, and Dispersibility of a Polystyrene/Montmorillonite Nanocomposite. Macromolecular Chemistry and Physics, 2001. 202(7): p. 1189-1193.

52. Corma, A., M. Renz, and C. Schaverien, Coupling Fatty Acids by Ketonic Decarboxylation Using Solid Catalysts for the Direct Production of Diesel, Lubricants, and Chemicals. ChemSusChem, 2008. 1(8-9): p. 739-741.

53. Collard, F.X. and J. Blin, A review on pyrolysis of biomass constituents: Mechanisms and composition of the products obtained from the conversion of cellulose, hemicelluloses and lignin. Renewable and Sustainable Energy Reviews, 2014. 38: p. 594-608.

54. Effendi, A., H. Gerhauser, and A.V. Bridgwater, Production of renewable phenolic resins by thermochemical conversion of biomass: A review. Renewable and Sustainable Energy Reviews, 2008. 12(8): p. 2092-2116.

55. Amen-Chen, C., H. Pakdel, and C. Roy, Production of monomeric phenols by thermochemical conversion of biomass: A review. Bioresource Technology, 2001. 79(3): p. 277-299.

56. Zhang, X., et al., Enhancement of jet fuel range alkanes from co-feeding of lignocellulosic biomass with plastics via tandem catalytic conversions. Applied Energy, 2016. 173: p. 418-430.

57. Oasmaa, A. and D. Meier, Norms and standards for fast pyrolysis liquids: 1. Round robin test. Journal of Analytical and Applied Pyrolysis, 2005. 73(2): p. 323-334.

58. Martínez, J.D., et al., Performance and emissions of an automotive diesel engine using a tire pyrolysis liquid blend. Fuel, 2014. 115: p. 490-499. 